\title{
Componentes de rendimento e características da carne e carcaça de novilhos confinados sob efeito do tamanho de partícula e da altura de colheita das plantas de milho na ensilagem
}

\author{
Yield composition and characteristics of meat and carcass of steers confineds on effect of particle \\ size and cutting height of corn plant for silage
}

\author{
Mikael Neumann' ${ }^{\mathrm{I}}$ João Restle ${ }^{\mathrm{II}}$ Paulo Roberto Frenzel Mühlbach ${ }^{\mathrm{III}}$ Luiz Giovani de Pellegrini ${ }^{\mathrm{IV}}$ \\ Margarete Kimie Falbo ${ }^{\text {IV }}$ Itacir Elói Sandini ${ }^{\mathrm{IV}}$
}

RESUMO

O experimento foi conduzido no Núcleo de Produção Animal (NUPRAN) da Universidade Estadual do Centro Oeste do Paraná (UNICENTRO) com o objetivo de avaliar o efeito do tamanho de partícula (pequena: entre 0,2 e 0,6 cm ou grande: entre 1,0 e 2,0 cm) e da altura de corte das plantas de milho para ensilagem (baixa: $15 \mathrm{~cm}$, ou alta: $39 \mathrm{~cm}$ ), sobre os componentes de rendimento e as características da carne e carcaça de novilhos terminados em confinamento, constituindo-se os tratamentos: $T_{1}$ - silagem de partícula pequena com altura de corte baixa; $T_{2}$ - silagem de partícula grande com altura de corte baixa; $T_{3}$ - silagem de partícula pequena com altura de corte alta; $e T_{4}$ - silagem de partícula grande com altura de corte alta. Não houve interação significativa $(P>0,05)$ entre altura de colheita e tamanho de partícula para os parâmetros relativos aos componentes de rendimento e às características da carne e carcaça. Silagens de partícula pequena na dieta alimentar de bovinos confinados proporcionaram maior $(P<0,05)$ rendimento de carcaça $e$ menores perdas no resfriamento, apesar de as demais características de carcaça mostrarem-se similares às silagens de partícula grande. A elevação da altura de colheita das plantas de milho de 15 para $39 \mathrm{~cm}$ durante a ensilagem não gerou alterações $(P>0,05)$ nas características da carcaça, na qualidade da carne e nos componentes de rendimento da carcaça na produção de novilhos de corte confinados.

Palavras-chave: perdas no resfriamento da carcaça, rendimento de carcaça, temperatura da carçaca.

\section{ABSTRACT}

The experiment was conducted at the Núcleo de Produção Animal (NUPRAN) of Universidade Estadual do
Centro Oeste do Paraná (UNICENTRO). The experiment was aimed at evaluating the composition of yield and characteristics of meat and carcass on effect of particle sizes (small: between 0.2 and $0.6 \mathrm{~cm}$ or large: between 1.0 and $2.0 \mathrm{~cm}$ ) and cutting heights (low cut: $15 \mathrm{~cm}$ or high cut: $39 \mathrm{~cm}$ ) of the corn plant. The treatments were: $T_{1}$ - small particle size with low cut height; $T_{2}$ - large particle size with low cut height; $T_{3}$ - small particle size with high cut height; and $T_{4}$ - large particle size with high cut height. No signification interaction $(P>.05)$ was observed between cutting height and particle size for composition of income and characteristics of meat and carcass. Small particle silages in diet for confined cattle production presented higher $\left(P_{-}<.05\right)$ dressing percentage and small refreshing losses in spite of others carcass characteristics were similar to larger particle size. The cutting height of corn plant for silage from 15 to $39 \mathrm{~cm}$ didn't no affect $(P>.05)$ the yield composition and characteristics of meat and carcass of steers confined.

Key words: carcass temperature, dressing percentage, refreshing losses.

\section{INTRODUÇÃO}

A avaliação dos componentes nãointegrantes das partes do corpo do animal e das características da carne e carcaça são muito importantes para o entendimento da relação do desempenho dos animais sob diferentes manejos alimentares às características da carcaça.

PACHECO et al. (2005a) relatam que os componentes não-integrantes da carcaça são

\footnotetext{
ICurso de Pós-graduação em Produção Vegetal, Universidade Estadual do Centro-Oeste do Paraná (UNICENTRO), Centro de Ciências Agrárias e Ambientais. Rua Simeão Camargo Varela de Sá, 03, 85040-080, Guarapuava, PR, Brasil. E mail: mikaelneumann@hotmail.com. Autor para correspondência.

IIPrograma de Pós-graduação em Zootecnia, Universidade Federal de Goiás (UFG), Goiânia, GO, Brasil.

IIIPrograma de Pós-graduação em Zootecnia, Universidade Federal do Rio Grande do Sul (UFRGS), Porto Alegre, RS, Brasil.

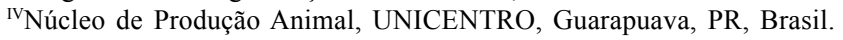


importantes para o frigorífico pela receita gerada com a comercialização no atacado, ou, no caso de gorduras, ossos, coração, rins e fígado, entre outros, pela agregação de valor na fabricação de embutidos e afins. De maneira geral, quanto maior o rendimento das partes não-integrantes da carcaça, maior o lucro do frigorífico e menor a remuneração por animal abatido repassado ao produtor devido à redução do rendimento da carcaça quente e/ou fria. Cabe ressaltar, no entanto, que é importante o estudo dos componentes não-integrantes da carcaça e das características da carne e carcaça, por estas estarem diretamente relacionadas ao rendimento de carcaça dos animais e às exigências nutricionais da categoria animal em questão (PACHECO et al., 2005b).

Dados de literatura (SIGNORETTI et al., 1999) mostram que o nível de fibra e/ou de energia na dieta alimentar de bovinos em fase de terminação podem alterar tanto os componentes não-integrantes da carcaça como as características da carne e carcaça e, consequentemente, alterar tanto a receita do frigorífico como do produtor, sem considerar a questão de qualidade de produto final ofertado aos consumidores de carne bovina.

A possibilidade de manipulação do processo de colheita do milho para ensilagem, com a elevação da altura de corte das plantas, e o aumento do tamanho da partícula na colheita da planta de milho são dois pontos importantes a se considerar durante a confecção de silagem, pois, além de determinarem diferenças técnicas quanto ao custo de produção, perdas de nutrientes e desempenho animal, podem alterar significativamente os componentes não-integrantes da carcaça, como as características da carne e carcaça, em função de variações promovidas por estes procedimentos na qualidade da dieta alimentar oferecida aos animais em sua fase de engorda e/ou terminação (RESTLE et al., 2000; RESTLE et al., 2002b; PACHECO et al., 2005a).

Aumentando a altura de corte das plantas, via regulagem na ensiladeira, somente a porção superior da planta de milho é colhida, resultando em silagem com maior participação de grãos na matéria seca. Segundo NUSSIO et al. (2001), a parte superior da planta de milho constitui uma silagem de maior concentração energética, indicada para uso em sistemas com animais de alta produção, em virtude de ser um alimento de alto valor nutricional e de maior custo de produção, por apresentar normalmente rendimentos de matéria seca de 75 a $80 \%$ em relação à silagem de planta inteira. Com a elevação da altura de corte das plantas, obtém-se menor participação de colmos e folhas senescentes, resultando, segundo RESTLE et al. (2002b), em melhoria da qualidade da silagem produzida devido aos decréscimos significativos nos teores de fibra em detergente neutro e detergente ácido da silagem.

Já na análise do tamanho da partícula ensilada, em nível prático de propriedades rurais, notadamente esta é muito variável e relaciona-se diretamente com a potência do trator e/ou a regulagem da ensiladeira utilizada. Porém, o menor tamanho da partícula, teoricamente, facilita o processo de ensilagem, uma vez que permite maior densidade de transporte do material colhido até o local de armazenamento, facilita o processo de compactação e permite melhor fermentação anaeróbia. Em conseqüência disso, preserva o valor nutritivo da massa ensilada e minimiza as perdas totais de matéria seca, mesmo com tendência de aumento nos teores de efluentes.

Este trabalho foi realizado com o objetivo de avaliar o efeito associativo do tamanho de partícula (pequena e grande) e da altura de corte das plantas (baixa e alta) sobre as características da carne e carcaça e componentes de rendimento de carcaça de novilhos confinados.

\section{MATERIAL E MÉTODOS}

O experimento foi conduzido no Núcleo de Produção Animal (NUPRAN) do Setor de Ciências Agrárias e Ambientais da Universidade Estadual do Centro-Oeste (UNICENTRO), em Guarapuava-PR, no período de 15 de outubro de 2004 a 15 de dezembro de 2005.

Para as variáveis relativas às características da carne e carcaça e componentes de rendimento de carcaça de novilhos confinados, foram avaliados os efeitos de dois tamanhos de picagem (partícula pequena de regulagem, entre 0,2 e $0,6 \mathrm{~cm}$, ou partícula grande de regulagem, entre 1,0 e $2,0 \mathrm{~cm}$ ) e duas alturas de corte das plantas para ensilagem (corte baixo, com média de $15 \mathrm{~cm}$, ou corte alto, com média de $39 \mathrm{~cm}$ ), num esquema fatorial 2 × 2: $\mathrm{T}_{1}$ - silagem de partícula pequena com altura de corte baixa; $\mathrm{T}_{2}$ - silagem de partícula grande com altura de corte baixa; $\mathrm{T}_{3}$ - silagem de partícula pequena com altura de corte alta; e $\mathrm{T}_{4}$ - silagem de partícula grande com altura de corte alta.

Como material experimental, empregaram-se as silagens do híbrido de milho P-30S40, de caráter silageiro de porte alto, produzidas em uma área de dois hectares, subdivida em 12 faixas de $1.700 \mathrm{~m}^{2}$. Foi utilizada uma adubação de base de $350 \mathrm{~kg} \mathrm{ha}^{-1}$ com o fertilizante 08-30-20 (N-P $\mathrm{O}_{5}-\mathrm{K}_{2} \mathrm{O}$ ) (CFS-RS/SC, 1995). Após 35 dias do plantio, foi feita uma adubação em cobertura com $120 \mathrm{~kg} \mathrm{ha}^{-1}$ de $\mathrm{N}$, na forma de uréia.

A colheita das plantas de milho, no estádio de grão pastoso, ocorreu nos dias 07 e 08 de março de 
2005, com o auxílio de uma ensiladeira marca JF-Z10, quando, de forma alternada, seis faixas de cultivo de milho foram colhidas com regulagem em tamanho de partícula pequena e seis faixas em tamanho de partícula grande, variando a cada três faixas a altura de corte em baixa ou alta. $\mathrm{O}$ material colhido de cada faixa de cultivo foi transportado, depositado em um local previamente nivelado e bem drenado, compactado com auxílio de um trator, em silos do tipo "semitrincheira" com as dimensões de 1,6m de largura, 10m de comprimento e $0,8 \mathrm{~m}$ de altura, sendo completamente vedados e protegidos com lona de polietileno de três camadas $(200 \mu)$. Deste modo, em função dos tratamentos avaliados, foram confeccionados 12 silos com capacidade aproximada de $8.000 \mathrm{~kg}$ cada.

As instalações foram constituídas de 12 baias semicobertas para o confinamento dos animais, com uma área de $15 \mathrm{~m}^{2}$ cada $(2,5 \times 6,0 \mathrm{~m})$ para três animais, com um comedouro de concreto, medindo $2,30 \mathrm{~m}$ de comprimento, $0,60 \mathrm{~m}$ de largura e $0,35 \mathrm{~m}$ de altura, além de um bebedouro metálico, regulado por bóia automática. Foram utilizados 36 novilhos inteiros, da raça Charolês, provenientes do mesmo rebanho, com idade média de 12 meses, peso vivo médio inicial de $355 \mathrm{~kg}$, com desvio padrão de $\pm 2,2 \mathrm{~kg}$, vermifugados e equilibrados por peso e condição corporal para cada baia.

A terminação dos animais teve duração de 98 dias, sendo 14 dias de adaptação dos animais às dietas e instalações experimentais e, seqüencialmente, quatro períodos de 21 dias de avaliação. Os animais foram terminados em confinamento, sendo alimentados, na forma ad libitum, duas vezes ao dia, às $6 \mathrm{~h}$ e às $17 \mathrm{~h} 30 \mathrm{~min}$

A dieta foi constituída pelas silagens dos quatro tratamentos $(62,7 \%)$ e concentrado peletizado $(37,3 \%)$. Na preparação do concentrado, foram utilizados os seguintes alimentos: farelo de soja, casca de soja, radícula de cevada, grãos de milho moídos, calcário calcítico, fosfato bicálcico e sal comum. As dietas, na matéria seca oferecida, apresentaram teores médios de $11,5 \%$ de proteína bruta, $2,3 \%$ de extrato etéreo, $0,55 \%$ de $\mathrm{Ca}$ e $0,35 \%$ de $\mathrm{P}$ e $0,19 \%$ de $\mathrm{Na}$. $\mathrm{Na}$ tabela 1, é apresentado a composição dos ingredientes das dietas experimentais.

Ao término do confinamento, obedecendo um jejum de sólidos de 12 horas, os animais foram pesados antes do carregamento para o frigorífico, obtendo-se o peso de fazenda. Os abates seguiram o fluxo normal de um abatedouro. Após o abate, com a remoção do couro e evisceração dos 36 animais, as carcaças foram identificadas, lavadas, pesadas e resfriadas $\mathrm{a}-2^{\circ} \mathrm{C}$, por 24 horas. Decorrido esse tempo, as carcaças foram novamente pesadas, obtendo-se o peso de carcaça fria e a estimação das perdas no resfriamento. Em seguida, realizou-se a avaliação subjetiva, sugerida por MULLER (1987), da conformação, seguindo-se uma escala de 1 a 18 pontos, na qual um valor maior indica melhor conformação. Por fim, avaliou-se a maturidade fisiológica das carcaças, seguindo-se uma escala de 1 a 15 pontos, na qual um valor maior indica menor grau de maturidade.

Nas carcaças, também foram mensuradas cinco medidas de desenvolvimento: comprimento de carcaça, que é a distância entre o bordo cranial medial do osso púbis e o bordo cranial medial da primeira costela; comprimento de perna, que é a distância entre a borda cranial medial do osso púbis e a articulação tíbio-tarsiana; comprimento de braço, que é a distância entre a tuberosidade do olecrano e a articulação rádiocarpiana; perímetro de braço, obtido na região mediana do braço circundando-o com uma fita métrica; e a espessura do coxão, medida por intermédio de compasso, perpendicularmente ao comprimento de carcaça, tomando-se a maior distância entre o corte que separa as duas meias-carcaças e os músculos laterais da coxa, conforme as metodologias sugeridas porMULLER(1987).

Após a realização dessas medidas, realizouse um corte perpendicular no músculo Longissimus

Tabela 1 - Teores percentuais de matéria seca (MS), matéria orgânica (MO), digestibilidade in vitro da MO (DIVMO), proteína bruta (PB), fibra em detergente neutro (FDN) e fibra em detergente ácido (FDA), com base na matéria seca total, dos componentes das dietas experimentais, em função do tamanho de partículas e da altura de colheita.

\begin{tabular}{|c|c|c|c|c|c|c|c|}
\hline \multicolumn{2}{|c|}{ Silagem } & \multicolumn{6}{|c|}{ Variável } \\
\hline Tamanho de partícula & Altura de colheita & MS (\%) & $\mathrm{MO}(\% \mathrm{MS})$ & DIVMO (\%) & $\mathrm{PB}(\% \mathrm{MS})$ & FDN (\% MS) & FDA $(\% \mathrm{MS})$ \\
\hline Pequena & Baixa & 28,89 & 95,79 & 58,16 & 5,56 & 59,00 & 30,09 \\
\hline Grande & Baixa & 29,13 & 95,91 & 57,50 & 6,05 & 58,32 & 29,85 \\
\hline Pequena & Alta & 28,96 & 96,04 & 56,39 & 5,85 & 56,06 & 28,61 \\
\hline Grande & Alta & 27,06 & 96,09 & 59,45 & 5,39 & 59,15 & 28,96 \\
\hline \multicolumn{2}{|c|}{ Média } & 28,51 & 95,96 & 95,96 & 5,71 & 58,13 & 29,38 \\
\hline \multicolumn{2}{|c|}{ Concentrado comercial } & 88,21 & 93,02 & 93,02 & 16,29 & 13,05 & - \\
\hline
\end{tabular}

Ciência Rural, v.38, n.2, mar-abr, 2008. 
dorsi, na altura da $12^{a}$ costela, onde foram avaliadas as características subjetivas: de cor, seguindo-se uma escala de 1 a 5 pontos, na qual um valor menor indica coloração mais escura; de textura, seguindo-se uma escala de 1 a 5 pontos, em que um valor menor indica textura muito grosseira; de marmoreio, seguindo-se uma escala de 1 a 18 pontos, na qual um valor maior indica marmoreio mais abundante; e de espessura de gordura (MULLER, 1987).

Para determinar a porcentagem de cortes comerciais, dividiu-se a meia carcaça esquerda em dianteiro, traseiro e costilhar e, por intermédio de pesagem, calculou-se a porcentagem destes em relação à meia carcaça.

No momento do abate, realizou-se a caracterização das partes do corpo não-integrantes da carcaça dos novilhos abatidos, através da coleta dos pesos dos seguintes componentes: cabeça, língua, rabo, patas e couro (denominados componentes externos); coração, rins, fígado, baço e pulmões (denominados órgãos vitais); diafragma, rúmen-retículo cheio, rúmen-retículo vazio, abomaso cheio, abomaso vazio, intestinos delgado e grosso cheios.

$\mathrm{O}$ delineamento experimental foi $\mathrm{o}$ inteiramente casualizado, composto por quatro tratamentos, com três repetições, em que cada repetição foi um silo e/ou uma baia, em um esquema fatorial $2 \times 2$, sendo dois tamanhos de partículas (pequena e grande) e duas alturas de colheita (baixa e alta). Na avaliação dos componentes de rendimento e características da carne e carcaça, considerou-se a baia (média de três animais) como unidade experimental. Os dados coletados para cada variável foram submetidos à análise de variância, com comparação das médias, a $5 \%$ de significância, por intermédio do programa estatístico SAS (1993). A análise de cada variável seguiu o modelo estatístico: $\mathrm{Y}_{\mathrm{ijk}}=\mu+\mathrm{TP}_{\mathrm{i}}+\mathrm{AC}_{\mathrm{j}}+(\mathrm{TP} * \mathrm{AC})_{\mathrm{ij}}+$ $\mathrm{R}_{\mathrm{l}}(\mathrm{TP} * \mathrm{AC})_{\mathrm{ij}}+\mathrm{E}_{\mathrm{ijk}}$; em que: $\mathrm{Y}_{\mathrm{ijkl}}=$ Variáveis dependentes; $\mu=$ Média geral de todas as observações; $\mathrm{TP}_{\mathrm{i}}=$ Efeito do tamanho da partícula da silagem de ordem "i”, sendo $1=$ pequena e $2=$ grande; $\mathrm{AC}_{\mathrm{j}}=$ Efeito da altura de colheita de ordem " $\mathrm{j}$ ", sendo 1 = baixa e 2 = alta; $(\mathrm{TP} * \mathrm{AC})_{\mathrm{ij}}=$ Efeito da interação entre o i-ésimo tamanho de partícula com a j-ésima altura de colheita; $\mathrm{R}_{\mathrm{k}}\left(\mathrm{TP}^{*} \mathrm{AC}\right)_{\mathrm{ij}}=$ Efeito aleatório baseado na repetição dentro da combinação $\left(\mathrm{TP}^{*} \mathrm{AC}\right)_{\mathrm{ij}}$; e $\mathrm{E}_{\mathrm{ijk} \mathrm{k}}=$ Efeito aleatório residual.

\section{RESULTADOS E DISCUSSÃO}

Não houve interação $(\mathrm{P}>0,05)$ entre altura de colheita e tamanho de partícula para as características da carne e da carcaça contidas na tabela 2. Na análise geral dos dados, verifica-se que os fatores altura de colheita e tamanho de partículas, de forma individual ou combinada, não afetaram $(\mathrm{P}>0,05)$ os pesos de saída da fazenda e os pesos de carcaça quente e de carcaça fria, apresentando valores médios, respectivamente de 484,06 ; de 262,45 e de $259,53 \mathrm{~kg}$. No entanto, maior rendimento de carcaça $(54,76$ contra $53,65 \%)$ e menores perdas no resfriamento de carcaça $(0,77$ contra $1,46 \%)$ foram observados nos animais cujas dietas continham como volumoso silagens de partícula pequena em relação às de partículas grandes. $\mathrm{O}$ maior rendimento de carcaça dos novilhos alimentados com silagem de partículas pequenas justifica-se pela menor eficiência de retenção destas partículas no trato gastrointestinal, em relação às partículas grandes, evidenciando, respectivamente, peso de retículo-rúmen cheio ao abate (36,86 contra $38,74 \mathrm{~kg}$, Tabela 3$)$.

RESTLE et al. (2002b), avaliando silagens de milho colhidas a 20 e $42 \mathrm{~cm}$ de altura na produção do superprecoce, verificaram que o peso final $(368,2$ contra $371,8 \mathrm{~kg})$, o rendimento de carcaça $(53,08$ contra $52,46 \%)$ e o peso de carcaça fria $(195,7$ contra $195,3 \mathrm{~kg})$ foram similares $(\mathrm{P}>0,05)$ para os animais alimentados com as duas silagens. No entanto, os mesmos autores também verificaram que a gordura de cobertura, embora sem diferença significativa $(\mathrm{P}=0,1322)$, foi numericamente superior nos animais que tiveram maior concentração energética na dieta $(3,67$ contra 5,67mm). RESTLE et al. (2000) também verificaram que a utilização da silagem de milho obtida através do corte alto $(46 \mathrm{~cm})$ para produção do superprecoce resultou em maior porcentagem de gordura na carcaça. Já RESTLE et al. (2002a), avaliando silagens de sorgo colhidas a 14 e $45 \mathrm{~cm}$ de altura na produção do superprecoce, observaram que o peso de abate dos animais foi de 382,7 e $363,0 \mathrm{~kg}$ para o tratamento com corte alto e baixo, respectivamente, e que o peso de carcaça fria e a espessura de gordura, citadas na mesma ordem, foram de $204,5 \mathrm{~kg}$ e $3,66 \mathrm{~mm}$, e de $196,7 \mathrm{~kg}$ e $4,02 \mathrm{~mm}$.

Os dados da tabela 2 também mostram que os fatores altura de colheita e tamanho de partículas, de forma individual ou combinada, não afetaram $(\mathrm{P}>0,05)$ a constituição física e os índices de $\mathrm{pH}$ das carcaças, apresentando valores médios de 49,81\% de serrote, $13,41 \%$ de costilhar, $36,76 \%$ de dianteiro e índice de 5,51 de $\mathrm{pH}$. Já na análise do parâmetro temperatura, verificou-se que animais alimentados com silagens de partículas pequenas produziram carcaças que tiveram melhor eficiência de resfriamento em 24 
Tabela 2 - Características da carne e da carcaça de novilhos confinados alimentados com silagens de milho, em função do tamanho de partícula e da altura de colheita.

\begin{tabular}{|c|c|c|c|}
\hline \multirow{2}{*}{$\begin{array}{l}\text { Sistema de } \\
\text { ensilagem }\end{array}$} & \multicolumn{2}{|c|}{ Altura de colheita das plantas } & \multirow[t]{2}{*}{ Média } \\
\hline & Corte baixo & Corte alto & \\
\hline \multicolumn{4}{|c|}{ Peso vivo de fazenda, $\mathrm{kg}$} \\
\hline Partícula pequena & 481,99 & 481,85 & $481,92 \mathrm{~A}$ \\
\hline Partícula grande & 480,07 & 492,31 & $486,19 \mathrm{~A}$ \\
\hline Média & $481,03 \mathrm{~A}$ & $487,08 \mathrm{~A}$ & \\
\hline \multicolumn{4}{|c|}{ Peso de carcaça quente, $\mathrm{kg}$} \\
\hline Partícula pequena & 260,00 & 267,78 & $263,89 \mathrm{~A}$ \\
\hline Partícula grande & 258,67 & 263,33 & $261,00 \mathrm{~A}$ \\
\hline Média & $259,33 \mathrm{~A}$ & $265,56 \mathrm{~A}$ & \\
\hline \multicolumn{4}{|c|}{ Peso de carcaça fria, $\mathrm{kg}$} \\
\hline Partícula pequena & 258,24 & 265,44 & $261,84 \mathrm{~A}$ \\
\hline Partícula grande & 255,22 & 259,24 & $257,23 \mathrm{~A}$ \\
\hline Média & $256,73 \mathrm{~A}$ & $262,34 \mathrm{~A}$ & \\
\hline \multicolumn{4}{|c|}{ Rendimento de carcaça, $\%$} \\
\hline Partícula pequena & 53,99 & 55,54 & $54,76 \mathrm{~A}$ \\
\hline Partícula grande & 53,82 & 53,48 & $53,65 \mathrm{~B}$ \\
\hline Média & $53,90 \mathrm{~A}$ & $54,51 \mathrm{~A}$ & \\
\hline \multicolumn{4}{|c|}{ Perdas no resfriamento de carcaça, $\%$} \\
\hline Partícula pequena & 0,69 & 0,85 & $0,77 \mathrm{~B}$ \\
\hline Partícula grande & 1,38 & 1,54 & $1,46 \mathrm{~A}$ \\
\hline Média & $1,03 \mathrm{~A}$ & $1,19 \mathrm{~A}$ & \\
\hline \multicolumn{4}{|c|}{ pH da carcaça resfriada, índice } \\
\hline Partícula pequena & 5,43 & 5,70 & $5,57 \mathrm{~A}$ \\
\hline Partícula grande & 5,43 & 5,46 & $5,45 \mathrm{~A}$ \\
\hline Média & $5,43 \mathrm{~A}$ & $5,58 \mathrm{~A}$ & \\
\hline \multicolumn{4}{|c|}{ Temperatura da carcaça resfriada, ${ }^{\circ} \mathrm{C}$} \\
\hline Partícula pequena & 10,11 & 9,67 & $9,89 \mathrm{~B}$ \\
\hline Partícula grande & 11,99 & 11,89 & $11,94 \mathrm{~A}$ \\
\hline Média & $11,05 \mathrm{~A}$ & $10,78 \mathrm{~A}$ & \\
\hline \multicolumn{4}{|c|}{ Porcentagem de serrote, \% } \\
\hline Partícula pequena & 49,83 & 49,67 & $49,75 \mathrm{~A}$ \\
\hline Partícula grande & 49,58 & 50,18 & $49,88 \mathrm{~A}$ \\
\hline Média & $49,70 \mathrm{~A}$ & $49,93 \mathrm{~A}$ & \\
\hline \multicolumn{4}{|c|}{ Porcentagem de costilhar, \% } \\
\hline Partícula pequena & 13,51 & 13,15 & $13,33 \mathrm{~A}$ \\
\hline Partícula grande & 13,17 & 13,83 & $13,50 \mathrm{~A}$ \\
\hline Média & $13,34 \mathrm{~A}$ & $13,49 \mathrm{~A}$ & \\
\hline \multicolumn{4}{|c|}{ Porcentagem de dianteiro, $\%$} \\
\hline Partícula pequena & 36,66 & 37,18 & $36,92 \mathrm{~A}$ \\
\hline Partícula grande & 37,24 & 35,99 & $36,61 \mathrm{~A}$ \\
\hline Média & $36,95 \mathrm{~A}$ & $36,58 \mathrm{~A}$ & \\
\hline
\end{tabular}

Médias, na linha ou na coluna, seguidas por letras maiúsculas diferentes diferem $(\mathrm{P}<0,05)$ pelo Teste "F".

horas pós abate $\left(9,89\right.$ contra $\left.11,94^{\circ} \mathrm{C}\right)$, se comparadas às silagens de partículas grandes, o que pode ser explicado pelo grau de marmorização da carne $(3,64$ contra 4,10 pontos, respectivamente).

$\mathrm{Na}$ tabela 4, são apresentados os valores médios das características da carcaça e qualidade da carne dos novilhos confinados alimentados com silagens de milho, em função do tamanho de partícula e da altura de colheita. $\mathrm{Na}$ análise dos dados, os fatores altura de colheita e tamanho de partículas, de forma individual ou combinada, não afetaram $(\mathrm{P}>0,05)$ espessura de gordura subcutânea, textura, cor e marmoreio da carne, apresentando, respectivamente, valores médios de 3,43mm, 3,11 pontos, 3,52 pontos e 
Tabela 3 - Pesos médios dos componentes de rendimento da carcaça de novilhos confinados alimentados com silagens de milho, em função do tamanho de partícula e da altura de colheita.

\begin{tabular}{|c|c|c|c|}
\hline \multirow{2}{*}{$\begin{array}{l}\text { Sistema de } \\
\text { ensilagem }\end{array}$} & \multicolumn{2}{|c|}{ Altura de colheita das plantas } & \multirow[t]{2}{*}{ Média } \\
\hline & Corte baixo & Corte alto & \\
\hline \multicolumn{4}{|c|}{ Peso da cabeça com língua, kg } \\
\hline Partícula pequena & 13,10 & 12,93 & $13,01 \mathrm{~A}$ \\
\hline Partícula grande & 13,82 & 13,48 & $13,65 \mathrm{~A}$ \\
\hline Média & $13,46 \mathrm{~A}$ & $13,20 \mathrm{~A}$ & \\
\hline \multicolumn{4}{|c|}{ Peso do rabo, $\mathrm{kg}$} \\
\hline Partícula pequena & 0,96 & 0,97 & $0,97 \mathrm{~A}$ \\
\hline Partícula grande & 0,90 & 0,94 & $0,92 \mathrm{~A}$ \\
\hline Média & $0,93 \mathrm{~A}$ & $0,95 \mathrm{~A}$ & \\
\hline \multicolumn{4}{|c|}{ Peso do coração, kg } \\
\hline Partícula pequena & 1,49 & 1,51 & $1,50 \mathrm{~A}$ \\
\hline Partícula grande & 1,46 & 1,48 & $1,47 \mathrm{~A}$ \\
\hline Média & $1,47 \mathrm{~A}$ & $1,49 \mathrm{~A}$ & \\
\hline \multicolumn{4}{|c|}{ Peso do fígado, $\mathrm{kg}$} \\
\hline Partícula pequena & 4,88 & 4,91 & $4,90 \mathrm{~A}$ \\
\hline Partícula grande & 4,98 & 4,92 & $4,95 \mathrm{~A}$ \\
\hline Média & $4,93 \mathrm{~A}$ & $4,92 \mathrm{~A}$ & \\
\hline \multicolumn{4}{|c|}{ Peso dos rins, $\mathrm{kg}$} \\
\hline Partícula pequena & 0,77 & 0,79 & $0,78 \mathrm{~A}$ \\
\hline Partícula grande & 0,83 & 0,81 & $0,82 \mathrm{~A}$ \\
\hline Média & $0,80 \mathrm{~A}$ & $0,80 \mathrm{~A}$ & \\
\hline \multicolumn{4}{|c|}{ Peso dos pulmões, $\mathrm{kg}$} \\
\hline Partícula pequena & 5,23 & 4,80 & $5,01 \mathrm{~A}$ \\
\hline Partícula grande & 5,03 & 5,15 & $5,09 \mathrm{~A}$ \\
\hline Média & $5,13 \mathrm{~A}$ & $4,98 \mathrm{~A}$ & \\
\hline \multicolumn{4}{|c|}{ Peso do retículo-rúmen cheio, $\mathrm{kg}$} \\
\hline Partícula pequena & 38,08 & 35,63 & $36,86 \mathrm{~B}$ \\
\hline Partícula grande & 37,61 & 39,88 & $38,74 \mathrm{~A}$ \\
\hline Média & $37,84 \mathrm{~A}$ & $37,76 \mathrm{~A}$ & \\
\hline \multicolumn{4}{|c|}{ Peso do retículo-rúmen vazio, $\mathrm{kg}$} \\
\hline Partícula pequena & 7,29 & 7,46 & $7,37 \mathrm{~A}$ \\
\hline Partícula grande & 7,41 & 7,73 & $7,57 \mathrm{~A}$ \\
\hline Média & $7,35 \mathrm{~A}$ & $7,59 \mathrm{~A}$ & \\
\hline \multicolumn{4}{|c|}{ Peso do abomaso cheio, $\mathrm{kg}$} \\
\hline Partícula pequena & 14,07 & 12,96 & $13,52 \mathrm{~A}$ \\
\hline Partícula grande & 13,05 & 13,21 & $13,13 \mathrm{~A}$ \\
\hline Média & $13,56 \mathrm{~A}$ & $13,09 \mathrm{~A}$ & \\
\hline \multicolumn{4}{|c|}{ Peso do abomaso vazio, $\mathrm{kg}$} \\
\hline Partícula pequena & 2,74 & 2,53 & $2,64 \mathrm{~A}$ \\
\hline Partícula grande & 2,55 & 2,58 & $2,56 \mathrm{~A}$ \\
\hline Média & $2,64 \mathrm{~A}$ & $2,55 \mathrm{~A}$ & \\
\hline \multicolumn{4}{|c|}{ Peso dos intestinos cheios, $\mathrm{kg}$} \\
\hline Partícula pequena & 19,09 & 18,76 & $18,92 \mathrm{~A}$ \\
\hline Partícula grande & 18,94 & 19,21 & $19,08 \mathrm{~A}$ \\
\hline Média & $19,02 \mathrm{~A}$ & $18,98 \mathrm{~A}$ & \\
\hline \multicolumn{4}{|c|}{ Peso do couro, $\mathrm{kg}$} \\
\hline Partícula pequena & 42,50 & 44,61 & $43,56 \mathrm{~A}$ \\
\hline Partícula grande & 43,90 & 43,92 & $43,91 \mathrm{~A}$ \\
\hline Média & $43,20 \mathrm{~A}$ & $44,27 \mathrm{~A}$ & \\
\hline
\end{tabular}

Médias, na linha ou na coluna, seguidas por letras maiúsculas diferentes diferem $(\mathrm{P}<0,05)$ pelo Teste " $\mathrm{F}$ ".

Ciência Rural, v.38, n.2, mar-abr, 2008. 
Tabela 4 - Características da carne e da carcaça de novilhos confinados alimentados com silagens de milho, em função do tamanho de partícula e da altura de colheita.

\begin{tabular}{|c|c|c|c|}
\hline \multirow{2}{*}{$\begin{array}{l}\text { Sistema de } \\
\text { ensilagem }\end{array}$} & \multicolumn{2}{|c|}{ Altura de colheita das plantas } & \multirow[t]{2}{*}{ Média } \\
\hline & Corte baixo & Corte alto & \\
\hline \multicolumn{4}{|c|}{ Espessura de gordura, $\mathrm{mm}$} \\
\hline Partícula pequena & 3,56 & 3,51 & $3,53 \mathrm{~A}$ \\
\hline Partícula grande & 3,69 & 3,11 & $3,40 \mathrm{~A}$ \\
\hline Média & $3,63 \mathrm{~A}$ & $3,31 \mathrm{~A}$ & \\
\hline \multicolumn{4}{|c|}{ Textura da carne, pontos } \\
\hline Partícula pequena & 3,29 & 2,97 & $3,13 \mathrm{~A}$ \\
\hline Partícula grande & 3,11 & 3,06 & $3,09 \mathrm{~A}$ \\
\hline Média & $3,20 \mathrm{~A}$ & $3,02 \mathrm{~A}$ & \\
\hline \multicolumn{4}{|c|}{ Cor da carne, pontos } \\
\hline Partícula pequena & 3,68 & 3,36 & $3,52 \mathrm{~A}$ \\
\hline Partícula grande & 3,49 & 3,56 & $3,52 \mathrm{~A}$ \\
\hline Média & $3,59 \mathrm{~A}$ & $3,46 \mathrm{~A}$ & \\
\hline \multicolumn{4}{|c|}{ Marmoreio, pontos } \\
\hline Partícula pequena & 3,68 & 3,61 & $3,64 \mathrm{~A}$ \\
\hline Partícula grande & 3,84 & 4,36 & $4,10 \mathrm{~A}$ \\
\hline Média & $3,76 \mathrm{~A}$ & $3,98 \mathrm{~A}$ & \\
\hline \multicolumn{4}{|c|}{ Maturidade da carcaça, pontos } \\
\hline Partícula pequena & 13,8 & 13,8 & $13,8 \mathrm{~A}$ \\
\hline Partícula grande & 14,0 & 14,0 & $14,0 \mathrm{~A}$ \\
\hline Média & $13,9 \mathrm{~A}$ & $13,9 \mathrm{~A}$ & \\
\hline \multicolumn{4}{|c|}{ Conformação da carcaça, pontos } \\
\hline Partícula pequena & 12,22 & 11,78 & $12,00 \mathrm{~A}$ \\
\hline Partícula grande & 11,94 & 12,67 & $12,31 \mathrm{~A}$ \\
\hline Média & $12,08 \mathrm{~A}$ & $12,22 \mathrm{~A}$ & \\
\hline \multicolumn{4}{|c|}{ Comprimento da carcaça, $\mathrm{cm}$} \\
\hline Partícula pequena & 125,9 & 123,9 & $124,9 \mathrm{~A}$ \\
\hline Partícula grande & 123,3 & 125,7 & $124,5 \mathrm{~A}$ \\
\hline Média & $124,6 \mathrm{~A}$ & $124,8 \mathrm{~A}$ & \\
\hline \multicolumn{4}{|c|}{ Comprimento da perna, $\mathrm{cm}$} \\
\hline Partícula pequena & 70,9 & 71,4 & $71,2 \mathrm{~A}$ \\
\hline Partícula grande & 70,0 & 70,6 & $70,3 \mathrm{~A}$ \\
\hline Média & $70,5 \mathrm{~A}$ & $71,0 \mathrm{~A}$ & \\
\hline \multicolumn{4}{|c|}{ Espessura de coxão, cm } \\
\hline Partícula pequena & 26,0 & 27,2 & $26,6 \mathrm{~A}$ \\
\hline Partícula grande & 26,8 & 27,4 & $27,1 \mathrm{~A}$ \\
\hline Média & $26,4 \mathrm{~A}$ & $27,3 \mathrm{~A}$ & \\
\hline \multicolumn{4}{|c|}{ Comprimento de braço, $\mathrm{cm}$} \\
\hline Partícula pequena & $38,2 \mathrm{~b}$ & $39,9 \mathrm{a}$ & 39,1 \\
\hline Partícula grande & $39,9 \mathrm{a}$ & $38,8 \mathrm{ab}$ & 39,4 \\
\hline Média & 39,1 & 39,3 & \\
\hline \multicolumn{4}{|c|}{ Perímetro de braço, $\mathrm{cm}$} \\
\hline Partícula pequena & 38,4 & 38,9 & $38,6 \mathrm{~A}$ \\
\hline Partícula grande & 38,6 & 38,6 & $38,6 \mathrm{~A}$ \\
\hline Média & $38,5 \mathrm{~A}$ & $38,7 \mathrm{~A}$ & \\
\hline
\end{tabular}

Médias seguidas por letras minúsculas diferentes diferem $(\mathrm{P}<0,05)$ pelo teste Tukey.

Médias, na linha ou na coluna, seguidas por letras maiúsculas diferentes diferem $(\mathrm{P}<0,05)$ pelo Teste "F".

3,87 pontos, como também não afetaram $(\mathrm{P}>0,05)$ a maturidade da carcaça, a conformação da carcaça, o comprimento da carcaça, o comprimento da perna, a espessura do coxão e o perímetro do braço, apresentando, respectivamente, valores médios de 13,9 pontos, 12,15 pontos, $124,7 \mathrm{~cm}, 26,8 \mathrm{~cm} \mathrm{e} 38,6 \mathrm{~cm}$.

Houve interação significativa entre altura 
de colheita e tamanho de partícula para comprimento de braço (Tabela 4). Menor $(\mathrm{P}<0,05)$ comprimento de braço foi observado para animais alimentados com silagem colhida à altura de $15 \mathrm{~cm}$ com partículas pequenas $(38,2 \mathrm{~cm})$, apesar de não diferir $(\mathrm{P}>0,05) \mathrm{da}$ silagem colhida a $39 \mathrm{~cm}$ de altura com partículas grandes $(38,8 \mathrm{~cm})$, em relação à silagem colhida à altura de $15 \mathrm{~cm}$ com partículas grandes $(39,9 \mathrm{~cm})$ e a $39 \mathrm{~cm}$ de altura com partículas pequenas $(39,9 \mathrm{~cm})$.

Nos dados da tabela 3, verifica-se que os fatores altura de colheita e tamanho de partículas, de forma individual ou combinada, não afetaram $(\mathrm{P}>0,05)$ os dos pesos de cabeça com língua, rabo, coração, fígado, rins, pulmões, baço e diafragma, apresentando, respectivamente, valores médios de 13,$34 ; 0,95 ; 1,48 ; 4,92 ; 0,80 ; 5,05 ; 1,50$ e 2,48kg. Além disso, esses fatores também não afetaram $(\mathrm{P}>0,05)$ os pesos do retículo-rúmen vazio e do abomaso cheio ou vazio, dos intestinos, couro e patas, apresentando, respectivamente, valores médios de 7,47; 13,32; 2,58; 19,$00 ; 43,73$ e $10,78 \mathrm{~kg}$.

A avaliação das partes não-integrantes da carcaça é importante, pois, segundo CUMBY (2000), o tamanho e a taxa metabólica dos órgãos vitais são diferentes em relação às demais partes do corpo do animal, podendo estar diretamente relacionados ao consumo de alimentos, desempenho animal e às exigências energéticas para mantença. FERREL \& JENKINS (1998) afirmam que o fígado, principal órgão responsável no metabolismo dos nutrientes, está entre os órgãos vitais que mais se modificam frente às variações no consumo de alimentos, exigências energéticas e taxas metabólicas.

Segundo RESTLE et al. (2005), para o frigorífico, os pesos absolutos de couro, língua, diafragma, retículo-rúmen, rabo, fígado, coração e ríns são importantes, uma vez que representam maior receita por unidade comercializada, fato também relatado por PACHECO et al. (2005a), indicando que é mais vantajoso $\mathrm{o}$ abate de animais mais pesados, pois geram maiores pesos absolutos das partes não-integrantes da carcaça.

Maior peso de retículo-rúmen cheio no abate dos animais (Tabela 3 ) foi verificado em animais cuja dieta incluía silagem de milho manipulada sob tamanho de partículas grandes $(38,74$ contra $36,86 \mathrm{~kg})$, comparativamente à silagem de partículas pequenas, fato este diretamente relacionado às diferenças obtidas no rendimento de carcaça dos animais (Tabela 2).

\section{CONCLUSÕES}

Silagens de partícula pequena na dieta alimentar de bovinos confinados proporcionaram maior rendimento de carcaça e menores perdas no resfriamento, apesar de as demais características de carcaça mostrarem-se similares às silagens de partícula grande.

A elevação da altura de colheita das plantas de milho de 15 para $39 \mathrm{~cm}$ durante a ensilagem não gerou alterações nas características da carcaça, na qualidade da carne e nos componentes de rendimento da carcaça, na produção de novilhos de corte superjovens.

\section{REFERÊNCIAS}

CUMBY. J. Visceral organ development during restriction and re-alimentation. In: CANT, J. (Ed.). COURSE IN RUMINANT DIGESTION AND METABOLISM - ANSC 6260, 2000, Guelph. Proceedings... Guelph: University of Guelph, 2000. p.23-29.

FERREL, C.L.; JENKINS, T.G. Body composition and energy utilization by steers of diverse genotypes fed high-concentrate diet during the finishing period: Angus, Boran, Brahman, Hereford and Tuli Sires. Journal of Animal Science, Savoy, v.76, p.647-657, 1998.

MULLER, L. Normas para avaliação de carcaças e concurso de carcaça de novilhos. 2.ed. Santa Maria: Universidade Federal de Santa Maria, 1987. 31p.

NUSSIO, L.G. et al. Importância da qualidade da porção vegetativa no valor alimentício da silagem de milho. In: JOBIM, C.C. et al. (Ed.). SIMPÓSIO SOBRE PRODUÇÃO E UTILIZAÇÃO DE FORRAGENS CONSERVADAS, 2001, Maringá, Anais... Maringá: UEM/CCA/DZO, 2001. p.127145 .

PACHECO, P.S. et al. Características das partes do corpo nãointegrantes da carcaça de novilhos jovens e superjovens de diferentes grupos genéticos. Revista Brasileira de Zootecnia, Viçosa, v.34, n.5, p.1678-1690, 2005a.

PACHECO, P.S. et al. Características quantitativas de carcaça de novilhos jovens e superjovens de diferentes grupos genéticos. Revista Brasileira de Zootecnia, Viçosa, v.34, n.5, p.1666$1677,2005 \mathrm{~b}$.

CFS-RS/SC. COMISSÃO DE FERTILIDADE DO SOLO - RS/ SC. Recomendações de adubação e calagem para os Estados do Rio Grande do Sul e Santa Catarina. 3.ed. Passo Fundo: SBCS-Núcleo Regional Sul, EMBRAPA-CNPT, 1995. 223p.

RESTLE, J.I.L. et al. Avaliação da altura de corte da silagem e dos níveis de concentrado na produção de terneiros para abate aos 12 meses de idade. 2 - Características da carcaça. In: REUNIÃO ANUAL DA SOCIEDADE BRASILEIRA DE ZOOTECNIA, 37., 2000, Viçosa. Anais... São Paulo: SBZ, Gmosis, [2000]. C D-ROM. Nutrição de Ruminantes. NUR-527.

RESTLE, J. et al. Manipulação do corte do sorgo (Sorghum bicolor, L. Moench) para confecção de silagem, visando a 
produção do novilho superprecoce. Revista Brasileira de Zootecnia, Viçosa, v.31, n.3 (S1), p.1481-1490, 2002a.

RESTLE, J. et al. Manipulação da altura de corte da planta de milho (Zea mays, L.) para ensilagem, visando a produção do superprecoce. Revista Brasileira de Zootecnia, Viçosa, v.31, n.3, p.1235-1244, 2002b.

RESTLE, J. et al. Características das partes do corpo nãointegrantes da carcaça de novilhos $5 / 8$ Nelore $3 / 8$ Charolês abatidos em três estádios de desenvolvimento. Revista
Brasileira de Zootecnia, Viçosa, v.34, n.4, p.1339-1348, 2005.

SAS INSTITUTE. SAS/STAT user's Guide: statistics, version 6.4.ed. North Caroline, 1993. V.2, 943p.

SIGNORETTI, R.D. et al. Características das partes nãointegrantes da carcaça animal e desenvolvimento do tratointestinal de bezerros da raça Holandesa alimentados com dietas contendo quatro níveis de concentrado. Revista Brasileira de Zootecnia, Viçosa, v.28, n.4, p.875-882, 1999. 